\title{
Small Bowel Obstruction due to Mesodiverticular Band of Meckel's Diverticulum: A Case Report
}

\author{
Aziz Sumer, ${ }^{1}$ Ozgur Kemik, ${ }^{1}$ Aydemir Olmez, ${ }^{1}$ A. Cumhur Dulger, ${ }^{2}$ Ismail Hasirci, ${ }^{1}$ \\ Umit Iliklerden, ${ }^{1}$ Erol Kisli, ${ }^{1}$ and Cetin Kotan ${ }^{1}$ \\ ${ }^{1}$ Department of Surgery, Faculty of Medicine, Yuzuncu Yil University, 65080 Van, Turkey \\ ${ }^{2}$ Departments of Gastroenterology, Faculty of Medicine, Yuzuncu Yil University, 65080 Van, Turkey
}

Correspondence should be addressed to Aziz Sumer, azizsumer2002@yahoo.com

Received 2 February 2010; Revised 30 May 2010; Accepted 16 July 2010

Academic Editor: Eldon A. Shaffer

Copyright () 2010 Aziz Sumer et al. This is an open access article distributed under the Creative Commons Attribution License, which permits unrestricted use, distribution, and reproduction in any medium, provided the original work is properly cited.

Meckel's diverticulum is the most common congenital anomaly of the small intestine. Common complications related to a Meckel's diverticulum include haemorrhage, intestinal obstruction, and inflammation. Small bowel obstruction due to mesodiverticular band of Meckel's diverticulum is a rare complication. Herein, we report the diagnosis and management of a small bowel obstruction occurring due to mesodiverticular band of a Meckel's diverticulum.

\section{Introduction}

Meckel's diverticulum is the most common congenital anomaly of the gastrointestinal system [1-3]. It originates from failure of the vitelline duct to obliterate completely, which is usually located on the antimesenteric border of the ileum. Its incidence is between $1 \%$ and $3 \%[2,4,5]$. Meckel's diverticulum occurs with equal frequency in both sexes, but symptoms from complications are more common in male patients. Most of the Meckel's diverticula are discovered incidentally during a surgical procedure performed for other reasons. Haemorrhage, small bowel obstruction, and diverticulitis are the most frequent complications. Histologically, heterotopic gastric and pancreatic mucosa are frequently observed in the diverticula of symptomatic patients $[1,3]$. Involvement of the mesodiverticular band of the diverticulum is seen rarely.

Herein, we were able to clearly demonstrate the mesodiverticular band. We reported the diagnosis and management of a small bowel obstruction due to mesodiverticular band of a Meckel's diverticulum.

\section{Case Report}

A 17-year-old male with no previous abdominal surgery, who experienced severe abdominal pain and vomiting one day earlier, was admitted to the emergency service of our hospital. His abdomen was very tender and distended, and bowel sounds were hyperactive. No masses were palpable. There was no significant medical history. His body temperature was $37^{\circ} \mathrm{C}$. Laboratory findings showed a leukocyte count of $9700 / \mathrm{mm}^{3}$, whereas the hemoglobin and platelet values were $13 \mathrm{~g} / \mathrm{dl}$ and $276,000 / \mathrm{mm}^{3}$, respectively. All other studies, including electrolytes and urinalysis, were within normal limits. Small intestine exhibited an air fluid level on the direct abdominal plain film. He was diagnosed with mechanical intestinal obstruction, and nasal decompression was performed. Emergency exploratory laparotomy was performed under general anesthesia. The distal part of the ileum was found to be markedly compressed by the mesodiverticular band within an area $60 \mathrm{~cm}$ proximal to the end of the ileum (Figure 1). Ileal loops were dilated at the superior part of the mechanical obstruction. Obstruction was caused by trapping of a bowel loop by a mesodiverticular band. After separating the mesodiverticular band from the mesenterium, the ileal loop was released from the diverticulum. Resection of the Meckel's diverticulum (Figure 2) and functional end-to-end anastomosis of the bowel were performed. The diverticulum was confirmed as Meckel's diverticulum by histological examination. The patient recovered without any complications and was discharged after five days of hospitalization. 


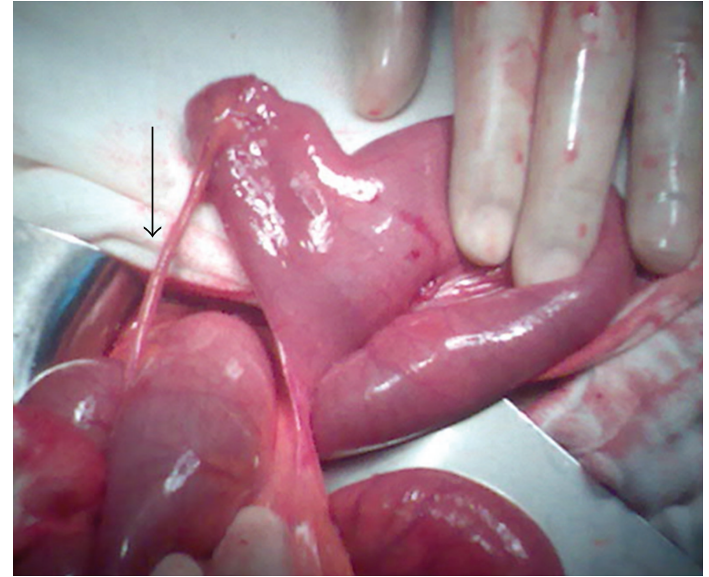

Figure 1: Meckel's diverticulum and mesodiverticular band (arrow).

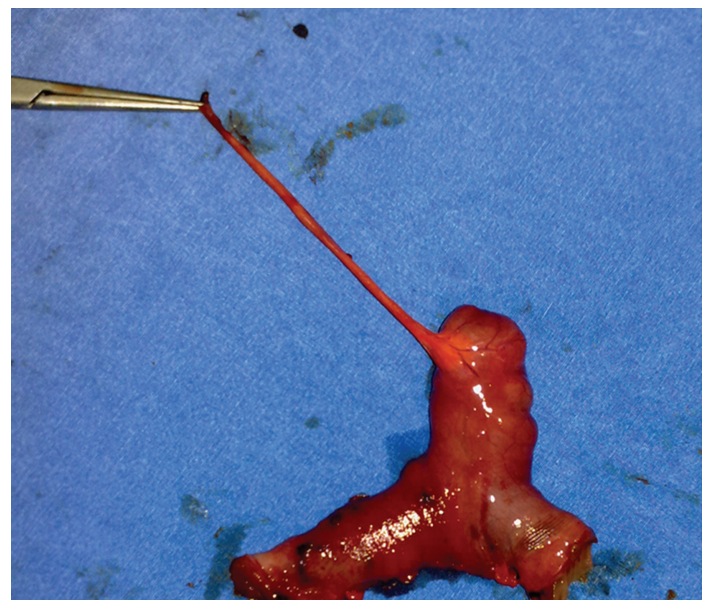

Figure 2: The view of resected Meckel's diverticulum and mesodiverticular band.

\section{Discussion}

Meckel's diverticulum was originally described by Fabricius Hildanus in 1598. However, it is named after Johann Friedrich Meckel, who established its embryonic origin in 1809 [6]. Meckel's diverticulum is the most common congenital anomaly of the small intestine, with a prevalence of approximately $1-3 \%$, and is a true diverticulum containing all layers of the bowel wall $[2,5-7]$. The average length of a Meckel's diverticulum is $3 \mathrm{~cm}$, with $90 \%$ ranging between $1 \mathrm{~cm}$ and $10 \mathrm{~cm}$ and the longest being $100 \mathrm{~cm}$. This diverticulum is usually found within $100 \mathrm{~cm}$ of the ileocaecal valve on the antimesenteric border of the ileum. The mean distance from the ileocaecal valve seems to vary with age, and the average distance for children under 2 years of age is known to be $34 \mathrm{~cm}$. For adults, the average distance of the Meckel's diverticulum from the ileocaecal valve is $67 \mathrm{~cm}$ [4]. Most cases that have Meckel's diverticulum are asymptomatic. Estimated risk for developing lifetime complications of the Meckel's diverticulum is around $4 \%$ $[2,5-7]$.

Most of the patients are asymptomatic, and the diagnosis is difficult to confirm preoperatively. Among the symptomatic patients, two types of heterotopic mucosa (gastric and pancreatic) are found histologically within the diverticula. The frequent complications of Meckel's diverticulum are hemorrhage, intestinal obstruction, and diverticulitis. Intestinal obstruction is the second most common complication of Meckel's diverticulum [3].

Elsayes et al. [1] noted that bowel obstruction accounts for up to $40 \%$ of symptomatic Meckel's diverticula. There are lots of mechanisms for bowel obstruction arising from a Meckel's diverticulum. Obstruction can be caused by trapping of a bowel loop by a mesodiverticular band, a volvulus of the diverticulum around a mesodiverticular band, and intussusception, as well as by an extension into a hernia sac (Littre's hernia) [1,3]. Similarly, as in our case, obstruction can be caused by trapping of a bowel loop by a mesodiverticular band. The important aspect of our case is clear demonstration of the mesodiverticular band of a Meckel's diverticulum. According to our literature review, this is the most evident mesodiverticular band view published until now.

Various imaging modalities have been used for diagnosing Meckel's diverticulum. Conventional radiographic examination is of limited value. Although of limited value, sonography has been used for the investigation of Meckel's diverticulum. High-resolution sonography usually shows a fluid-filled structure in the right lower quadrant having the appearance of a blind-ending, thick-walled loop of bowel. On computed tomography (CT), Meckel's diverticulum is difficult to distinguish from normal small bowel in uncomplicated cases. However, a blind-ending fluid or gasfilled structure in continuity with small bowel may be revealed. Abdominal CT is used for complicated cases such as intussusceptions. CT can help to confirm the presence of intussusception and distinguish between lead point and nonlead point intussusceptions $[2,8,9]$.

Among the asymptomatic patients, whether all incidental Meckel's diverticula should be resected or not is an unresolved question. On the other hand, for the symptomatic patients, treatment should always include resection of the diverticulum or the segment of the bowel affected by the pathology $[3,10]$.

In conclusion, although Meckel's diverticulum is the most prevalent congenital abnormality of the gastrointestinal tract, it is often difficult to diagnose. The complications of Meckel's diverticulum should be kept in mind in the differential diagnosis of small bowel obstruction.

\section{References}

[1] K. M. Elsayes, C. O. Menias, H. J. Harvin, and I. R. Francis, "Imaging manifestations of Meckel's diverticulum," American Journal of Roentgenology, vol. 189, no. 1, pp. 81-88, 2007.

[2] G. Dutta, A. S. Chowdhury, and M. Panda, "Band of cacophony-abdominal catastrophe caused by the fibrous band of Meckel's diverticulum: a case report," Cases Journal, vol. 2, no. 7, article 7160, 2009. 
[3] O. Karatepe, C. Dural, C. Erçetin et al., "Rare complication of Meckel's diverticulum: loop formation of diverticulum," Turkish Journal of Medical Sciences, vol. 38, no. 1, pp. 91-93, 2008.

[4] J. Dumper, S. Mackenzie, P. Mitchell, F. Sutherland, M. L. Quan, and D. Mew, "Complications of Meckel's diverticula in adults," Canadian Journal of Surgery, vol. 49, no. 5, pp. 353357, 2006.

[5] A. Tekin and T. Küçükkartallar, "Meckel Divertikülü'nün Nadir Bir Komplikasyonu: Ileus," Firat Tip Dergisi, vol. 1, pp. 62-64, 2008.

[6] K. W. Chan, "Perforation of Meckel's diverticulum caused by a chicken bone: a case report," Journal of Medical Case Reports, vol. 3, article 48, 2009.

[7] A. Sarioglu-Buke, N. Corduk, U. Koltuksuz, M. Karabul, B. Savran, and S. Bagci, "An uncommon variant of Meckel's diverticulum," Canadian Journal of Surgery, vol. 51, no. 2, pp. E46-E47, 2008.

[8] A. A. Malik, Shams-ul-Bari, K. A. Wani, and A. R. Khaja, "Meckel's diverticulum-revisited," Saudi Journal of Gastroenterology, vol. 16, no. 1, pp. 3-7, 2010.

[9] T. H. Lee, J.-O. Kim, J. J. Kim et al., "A case of intussuscepted Meckel's diverticulum," World Journal of Gastroenterology, vol. 15, no. 40, pp. 5109-5111, 2009.

[10] G. Clemente, R. Ionta, G. Sarno, R. Ricci, and G. Nuzzo, "Calcified Meckel's diverticulum: an unusual incidental finding during laparoscopy," American Journal of Surgery, vol. 193, no. 4, pp. 482-483, 2007. 


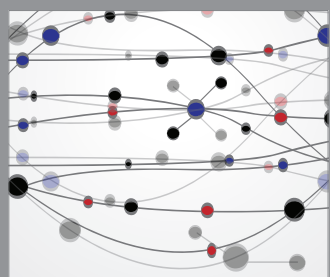

The Scientific World Journal
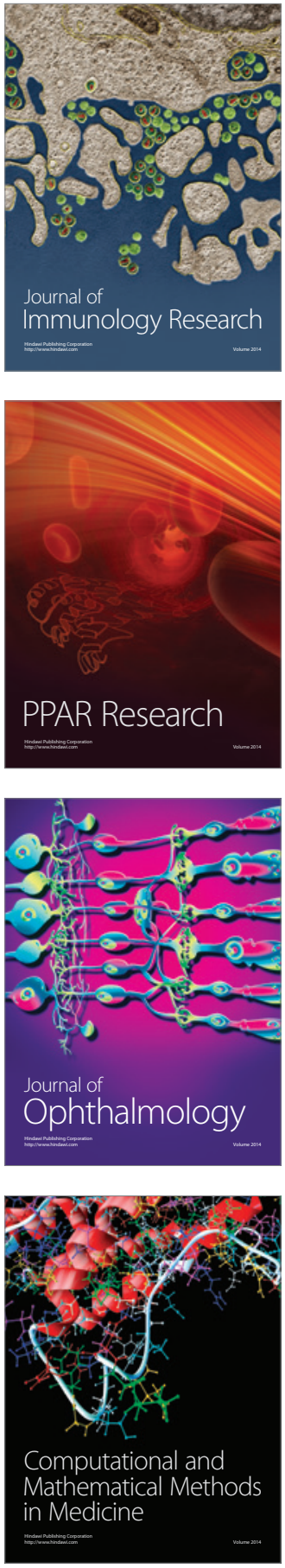

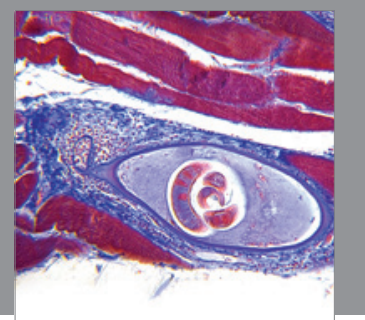

Gastroenterology

Research and Practice
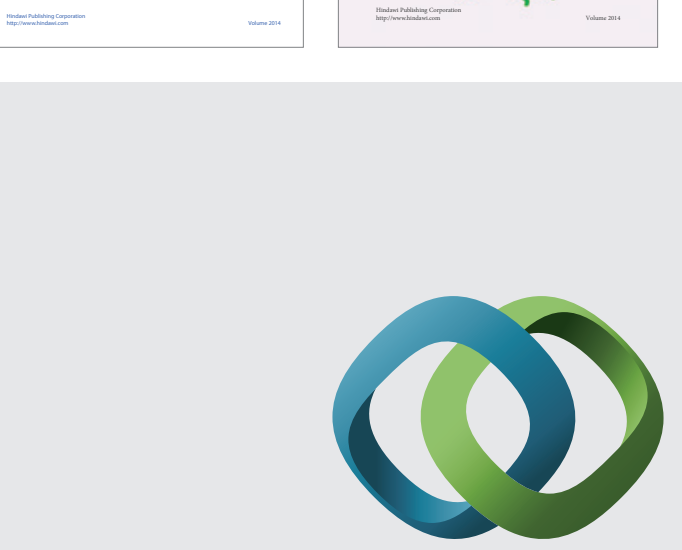

\section{Hindawi}

Submit your manuscripts at

http://www.hindawi.com
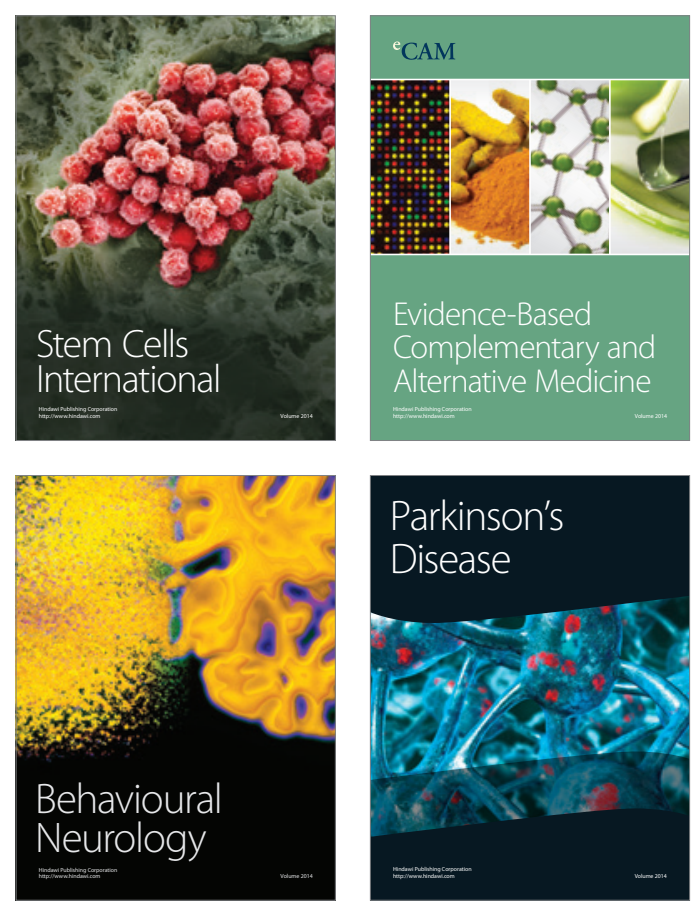

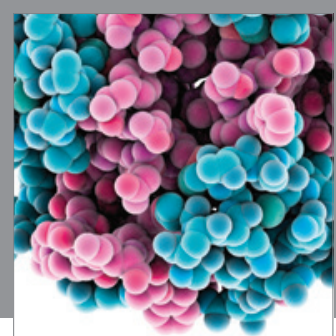

Journal of
Diabetes Research

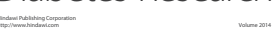

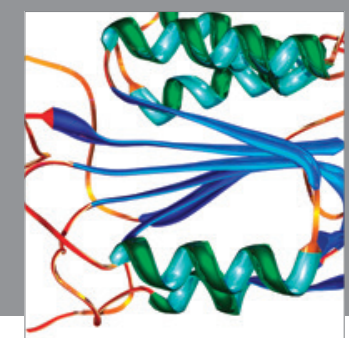

Disease Markers
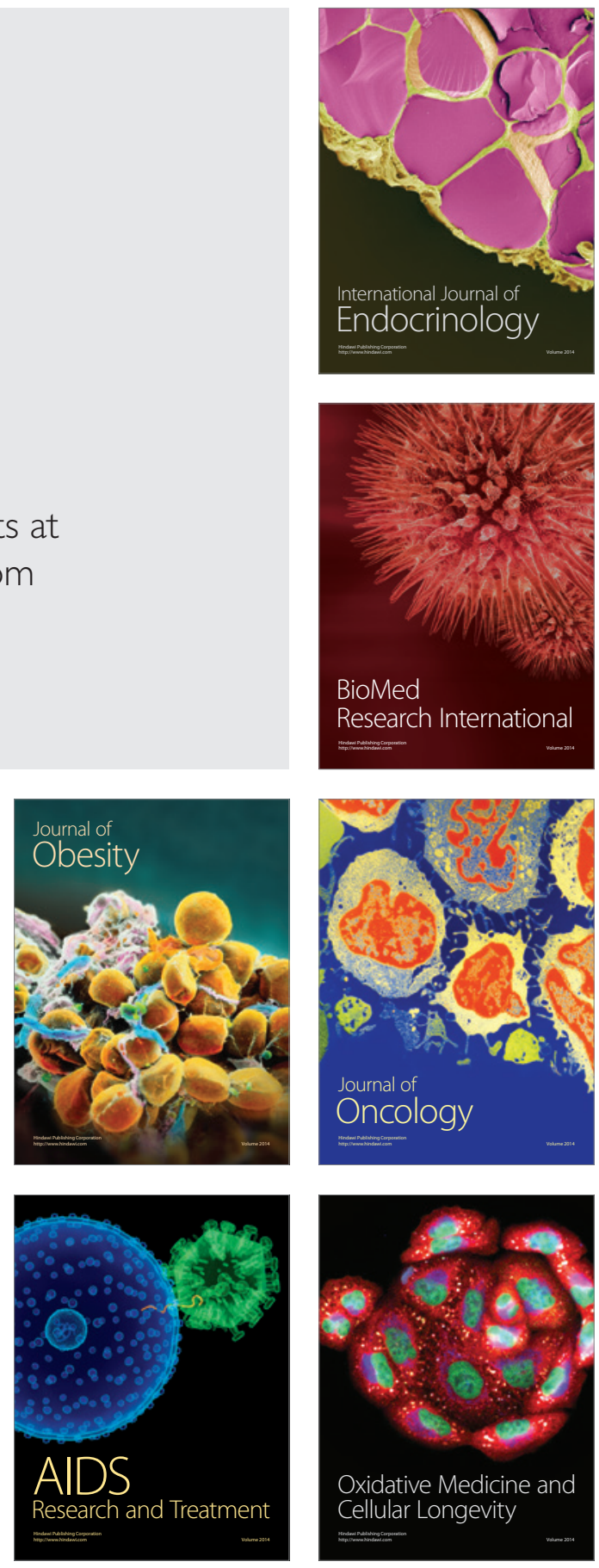